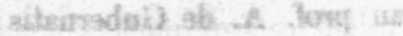

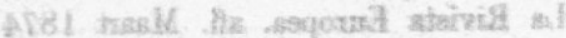

\section{STE BESTUURSVERGADERING,} GEHOUDEN 17 MAART 1874

79b asaleact

ashus nes Tegenwoordig de heeren: Bleeker (Voorzitter), Wijncsobutermalen (Secretaris), van der Gon Netscher (Penningmescun meester), Robidé van der $\mathbf{A a}$, Blommendal, Kern, -od gar Niemann en Schlegel. Afwezig de heeren 's Jacob, Millard, Meinsma en Sloet van de Beele, de beide laatste ies, ink met kennisgeving.

\section{arsecaltos}

De notulen van het verhandelde in de vorige vergadering worden gelezen en goedgekeurd.

De Voorzitter bericht de ontvangst van de volgende boekwerken :

Van het Departement van Koloniën :

Jaarboek van het mijnwezen in Ned. O. I. 2e jaarg. 2e dl. chs Beschrijving van Atjeh met kaart van de kust van Atjeh hassit en schetskaart van het Rijk Atjeh.

Van het Kon. Instituut van Ingenieurs :

asider Tïjdschrift, 1873-1874. 2e afl.

Van de Société de géographie, te Parijs:

asb Bulletin. Jan. en Febr. 1874.

Van de Société entomologique de France :

Bulletiu des séances, no. 21-22.

Van de K. Gesellschaft der Wissenschaften und der GeorgAugusts-Universität:

sah Nachrichten. 1873.

Van de Kais. Academie der Wissenschaften, te Weenen :

maditzungsberichten der math naturwissenschaftl. classe. 1874

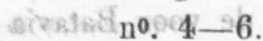

Van de K.9Preussische Academie der Wissenschaften, te Berlịn : ramo Monatsbericht. Dec. 1873.

Van professor Weber, afzonderlijke afdrukken van stukken voortomende in de Monatsberichten der Acad. v. wissensch. te Berlijn.

Vau den heer Guido Cora:

- Cosmos. VI. 
Van prof. A. de Gubernatis:

La Rivista Europea. afl. Maart 1874.

Van den heer Markham:

Ocean Highways. afl. Maart 1874.

In de eerste plaats wordt overgegaan tot het opmaken der drietallen, die op de aanstaande algemeene vergadering zullen worden aangeboden bij de verkiezing van drie bestuursleden, ter vervanging van de heeren Blommendal, Millard en Niemann, an wie dit jaar de beurt van aftreding is. De vergadering bepaalt dat

het drietal, ter vervanging van den heer Blommendal, zal bestaan uit de heeren: J. M. Obreen, professor J. Hoffmann en Dr. A. W. J. Juynboll;

het drietal, ter vervanging van den heer Millard, uit de heeren: Jhr. mr. W. T. Gevers Deynoot, Jhr. mr. J. K. W. Quarles van Ufford eu mr. D. J. Baron Mackay;

het drietal, ter vervanging van den heer Niemann, uit de heeren P. J. Bachiene, A. P. Godon en dr. F. A. C. Dumontier.

]) Voorzitter bericht de ontvangst van de volgende brieven:

10. Vau de Directie der stoomvaartmaatschappij "Nederland" te Ansterdam, waarbij die maatschappij zich bereid verklaart de vracht van door het Instituut naar Java te verzenden kistjes laag te stellen. Onder anderen zal voor een kistje van $93 \mathrm{~d}$. $\mathrm{M}^{3}$, zooals thans gereed is, niet meer berekend worden dan ${ }_{1}^{\frac{1}{0}} \mathrm{M}^{3}$ gewoon koopmansgoed $=f 2.50$, benevens de vracht van den Haag naar Amsterdam.

De vergadering is eenstemmig van gevoeleu dat, nu de kosten van verzending betrekkelijk slechts geriug zijn, het in het belang van de Indische leden, ten einde hen spoediger in het bezit der Werken en Bijdragen te stelleu, wenschelijk is de verzending voortaan door genoemde maatschappij te doen plaats hebben. Daar het tot nu toe niet de gewoonte was de voor Batavia bestemde kistjes te assureeren, wordt besloten die gewoonte te blijven volgen, teuzij door de vergadering ten aanzien eener expeditie in tegenovergestelden zin mocht worden beslist. Voor elke expeditie zal dus vooraf door het Bestuur worden bepaald of het te verzenden kistje al dan niet zal worden geassureerd.

20. Van den Nederlandschen Consul te Calcutta, ten geleide 3e Volgr. IX. 
van een schrijven namens den Luitenant-Goeverneur vay Bengalen, waarbij ter voldoening aan de uitnoodiging van het Instituut wordt toegezonden een exemplaar van Dalton's werk "Descriptive Ethnologie of Bengal." Daarbij zijn bovendien gevoegd een exemplaar van het werk: "Ethuology of India" door den heer George Campbelt en drie exemplaren van "Specimens of foure of the languages spoken in India." In dat schrijven wordt verklaard dat de Luitenant-Goeverneur mich voorstelt het Institunt een exemplaar toe te zenden vam werken op ethonologisch gebied, waarvan de uitgave op zịn last plaats vindt.

Een later schrijven van denzelfden Consul bericht de afyending van het kistje per stoomschip Cathay van Calcutta naar Southamptou en geeft het adres op waar de kosten van verzending, tot een bedrag vau 15 Shillings, kunnen worden voldaan.

Ins In overleg met den heer Nijhofl heeft de Secretaris zich bereids gewend tot de firma Smith en Co., te Rotterdam, met verzoek voor de overzending van evengenoemde werken van Southampton naar den Haag en voor de voldoening der kosten aan het opgegeven adres te Londen te willen zorg dragen, Deze firma heeft zich daartoe bereid verklaard, zoodat het kistje bimnen kort te verwachten is.

De vergadering draagt den Secretaris op, na ontvangst van het kistje, den Luitenant-Goeverneur dank te zeggen voor de welwillende en vriigevige wijze, waarop hij aan het verzoek van het Bestuur heeft willen voldoen en tevens den Nederlandschen Consul de erkentelijkheid van het Bestuur te betuigen voor zijne yerleende tusschenkomst.

30. Van den heer R. van Eck, zendeling op Bali Boelèlèng, gedagteekend 10 Januari 1874, van den volgenden inhoud: "Naar aanleiding van een schrijven van den heer Niemann, neem ik de vrijheid $\mathrm{U}$ bij deze te berichten, dat het eerste gedeelte van de door mij beloofde Balineesche gedichten _m zijnde de Bagoes Hoembara, groot 933 koepletten, tekst en vertaling

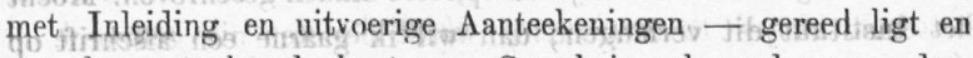
met de eerstvolgende boot naar Soerabaja zal worden gezonden. Allerlei omstandigheden waren oorzaak, dat ik eerst nu daaraan kou voldoen. (). a. heeft de vertaling, waarop ik miet gerekend had, mij veel tijd gekost. Eene oppervlakkige inzage van den tekst met de daaraan toegevoegde Aanieekeningen, zal dat begrijpelijk maken. Aangerien het Balineesch nog zoo weinig bekend 
is, heb $\mathrm{ik}$ om de herkenning van het oorspronkelịke gemakkelijk te maken, zoo letterlijk mogelijk vertaald. Het recht verstand van het Balineesch zal daardoor gewonnen hebben, wat het Hollandsch misschien verloor. Ik kon dit laatste te eerder doen, wijl - gelijk uit mijn schrijven aan den heer Niemann blijkt L de bedoeling was om alleen den Balineeschen fekst met de Aanteekeningen - die daarop ook zijn ingericht - te drukken. Mocht daarom het fnstituut soms besluiten om ook de vertaling uit te geven, dan zou 't mị zeer aangenaam zijn, zoo iemand de vriendelịkheid wilde hebben om mijn handschrift over te schrijven en daarin des noods al die veranderingen te maken die, zonder aan den inhoud te kort te doen, het ongegebondene - om mij zoo uit te drukken - van den Balineeschen stijl kunnen wegnemen. Ik zou dit natuurlijk liefst zelf doen, maar ik vrees dat het heen en weêr zenden te veel tijd zal kosteu, vooral ook wijl ik in het hier besproken geval er op gesteld zou zịn om eene laatste revisie van het gedrukte te mogen ontvangen.

"De Balineesche tekst met aanteekeningen heb ik, gelijk U zien zult, duidelijk geschreven en nauwkeurig nagezien, zoodat die zonder verdere korrektie van mịne zijde, in Holland kunnen worden afgedrukt. Om dezelfde reden koos ik daartoe goed stevig papier. Ik krịg mu echter een pakket ( $\pm 10 \times 24$ bladzijden) dat veel te groot is om met de gewone post verzonden te worden, zoodat ik genoodzaakt ben het naar Soerabaja te sturen, met verzoek om een en ander met het eerstvolgende stoomschip naar Holland te expedieëren en $\mathrm{U}$ het cognossement over te maken. De kosten hoop ik $\mathrm{U}$ later op te geven.

"Een kort bericht van de goede ontvangst - desnoods door toezending van een nummer van 't Haagsche Dagblad - zal mỉ zeer angenaam zijp.

"Na veel zoekens ben ik er eindelijk in geslaagd een kompleet exemplaar van de Bagoes Hoembara machitig te worden. 't Is echter eenigszins onduidelijk en op losse bladen geschreven. Mocht het Instituut dit verlangen, dan wil ik gaarne een afschrift op gelooide bladen daarvan laten maken. Meer dan $f 20$ zal dit niet kosten.

"De andere door mịj beloofde gedichten zij̄u de helft en meer kleiner dan dit. Zoodra de tijd mịj zulks toelat en ik weet dat het Instifuut ook na kennismaking met de Bagoes Hoembara bij zijn besluit blijft, om ook de uitgave daarvan op zich 
te nemen, hoop ik met de Pan Bongkling een aąivang te maken. Van dit gedicht is een kort uittreksel te vinden in eene kleine Handleiding bij de beoefening van het Balineesch, die, naar ik vertrouw, in deze of de volgende maand bij Kemink en Zoon het licht zal zien.

If " In de Aanteekeningen , behoorende bij de Bagoes Hoembara is hier en daar verwezen naar de Mégantaka, een BalineeschJavaansch gedicht, waarvan het Bat. Genootschap v. K. en Wetenschappen de uitgave op zich genomen heeft en waarvan reeds het zevende vel is afgedrukt.

tus In den Balineeschen tekst zijn enkele woorden onderstreept, die ik verzoek dat met gewone kursief-letters mogen worden gedrukt, terwijl andere, die dubbel onderstreept zijn, met eene dikkere letter volstaan kunnen.

"Voor overige bizonderheden verwijs ik naar de Inleiding.

"Hopende dat het Instituut met mijnen leekenarbeid tevreden zal zijn, heb ik de eer," enz.

De vergadering besluit de ontvangst van het handschrift af te wachten, alvorens omtrent den inhoud van dit schrijven en de uitgave van het verzonden handschrift een besluit te nemen.

De Secretaris zegt, dat hij den heer Couvée bekend heeft gemaakt met het besluit der vorige vergadering en dat de heer Couvée de voorwaarde om hem viermalen in het jaar, telkens gedurende drie dagen, beschikking over de localen te geven, heeft teruggenomen. De heer Couvée gaf evenwel in overweging de huur slechts voor één jaar te vernieuwen, op de voorwaarde van verhoogden huurprijs tegenover bevoegdheid voor het Instituut of Indisch Genootschap tot beschikking over het portaal tot het plaatsen van boekenkasten.

De vergadering machtigt hierop den Secretaris een contract met den heer Couvée in bedoelden zin aan te gaan.

Tex Tot leden van het Instituut worden voorgesteld en benoemd de heeren : J. H. F. Sollewijn Gelpke, te Leiden, en dr. H. Smeding, te Haarlem.

De heeren Rodidé van der $\mathrm{Aa}$ en Blommendal bieden het Bestur ter opneming in de Bijdragen aan een opstel van den heer Leupe over de tochten der Nederlaniders naar Nieuw-Guinea 